\title{
PENGARUH MODEL PERMAINAN TARGET TERHADAP AKURASI MENGUMPAN DALAM PERMAINAN SEPAK TAKRAW
}

\author{
Moh. Hanafi ${ }^{*}$, Abdul Aziz Hakim², Arif Bulqini ${ }^{3}$ \\ ${ }^{1}$ Jurusan Pendidikan Jasmani, Universitas PGRI Adi Buana Surabaya, Surabaya, Indonesia \\ ${ }^{2} J u r u s a n$ Pendidikan Kesehatan dan Rekreasi, Universitas Negeri Surabaya, Surabaya, Indonesia \\ ${ }^{3}$ Jurusan Pendidikan Kepelatihan Olahraga, Universitas Negeri Surabaya, Surabaya, Indonesia \\ *hanafi@unipasby.ac.id
}

(Received: June 2020/Revised: June 2020 / Accepted: July 2020)

\begin{abstract}
ABSTRAK: Permainan target dapat digunakan untuk membantu pemain meningkatkan keterampilan mengumpan dan akurasi mengumpan sehingga pemain dapat terlatih untuk melakukan umpan kearah sasaran secara tepat, atlet dapat mengumpan sesuai sasaran yang ditetapkan dengan tingkat akurasi yang tinggi. Permainan target juga merupakan permainan yang menyenangkan sehingga atlet tidak akan jenuh mengikuti treatment untuk mengatasi kesulitan mengumpan tepat sasaran. Metode latihan biasanya menggunakan metode drill. Kali ini peneliti yang juga sebagai pelatih sepak takraw akan mencoba menggunakan target lingkaran dalam upaya meningkatkan kemampuan akurasi umpan seorang. Penelitian ini termasuk jenis penelitian eksperimen. Pada penelitian ini, pengaruh yang dilihat adalah pengaruh permainan target terhadap kemampuan mengumpan. Hasil penelitian ini sebagian besar atlet mengalami peningkatan dalam tes ketepatan mengumpan. Hal ini dapat dilihat bahwa sebagian besar atlet memiliki skor selisih yang besar. Skor selisih tersebut diperoleh dengan mengurangkan skor post - test dengan skor pre - test. Dari 20 anak, hanya tiga anak yang tidak mengalami peningkatan ketepatan mengumpan setelah melakukan 6 kali treatement selama 12 kali pertemuan.

KATA KUNCl: Permainan Target, Ketepatan, Akurasi, Sepak Takraw

ABSTRACTS: The target game can be used to help players improve their passing skills, and accuracy in passing so that players can be trained to pass precisely towards the target, athletes can feed according to the targets set with a high degree of accuracy. The target game is also a fun game so that athletes will not get bored with taking treatment to overcome the difficulty of passing on target. This time the researcher who is also a sepak takraw coach will try to use the target circle in an effort to improve the accuracy of a bait. This research is an experimental research. Experimental research is research to look for the effect of certain treatments on controlled conditions. In this study, the effect seen was the effect of target play on the ability to pass. The results of this study most of the athletes experienced an increase in accuracy testing. It can be seen that most athletes have large difference scores. The difference score is obtained by subtracting the post-test score from the pre-test score. Of the 20 children, only three children who did not experience improved feeding accuracy after 6 treatments during 12 meetings

KEYWORD: $\quad$ Game Target, Accuracy, Sepak Takraw
\end{abstract}

\section{PENDAHULUAN}

Olahraga Sepak Takraw berkembang begitu lambat di Indonesia tidak seperti cabang olahraga permainan lainnya seperti sepak bola, bola voli, tenis lapangan dan bulutangkis. Jika dibandingkan dengan olahraga permainan lainya olahraga sepak takraw tidak membutuhkan peralatan yang mahal dan lapangan yang luas. Olahraga sepak takraw boleh dimainkan Page | 23 dilapangan terbuka maupun ruangan tertutup, sarana dan prasarana yang digunkan cukup sederhana lapangan dengan ukuran panjang 13.40 meter lebar 6.10 meter, bola sepak takraw dan net, jika tidak mau membuat cukup menggunakan lapangan bulutangkis cukup membawa bola sepak takraw saja karena ukuran lapangan sepak takraw dan bulutangkis panjang, lebar dan tinggi netnya sama. Sepak takraw merupakan salah satu olahraga tradisional yang ISSN 2620-6668 (cetak) 
berkembang dengan baik di Indonesia, yang mana banyak ditemukan di daerah dan kota besar. Perkembangan sepak takraw sebagai olahraga yang dipertandingkan telah menyebar secara Nasional, Regional dan PON, SEA Games dan Asian Games, sedangkan pada tingkat Olympiade masih diperjuangkan (Hanif 2015:1). Sepaktakraw adalah olahraga yang attraktif yang dimainkan oleh oleh semua anggota tubuh kecuali tangan dengan menggunakan bola terbuat dari rotan/fiber, jumlah pemain Sepaktakraw dalam satu regu 5 (lima) orang 3 (tiga) pemain inti dan 2 (dua) pemain cadangan Moh Hanafi, Abdul Aziz Hakim, Arif Bulqini (2016).

Permainan Sepak takraw identik dengan bola rotan istilah modern sekarang disebut bola bocor, dalam bermain sepak takraw ada tiga posisi yaitu smash disebut killer servis disebut tekong dan pengumpan disebut feeder. Feeder atau pengumpan harus mengumpan dengan baik untuk melayani seorang smeser baik saja tidak cukup melainkan harus ditingkatkan dengan akurasi yang tinggi agar bola tidak mudah diblok oleh lawan. Kesalahan seorang smeser sering kali terjadi karena umpan yang salah dan kurang baik untuk itu tingkat akaurasi umpan harus lebih dioptimalkan agar smeser menjalankan tugasnya dengan baik untuk meraih angka.

Permainan target adalah klasifikasi dari bentuk permainan dalam pendekatan prinsip latihan dimana dalam prinsip latihan ada variasi latihan supaya menghilangkan kejenuhan dalam proses latihan. Dalam Sofyan Hanif, (2015) latihan mengumpan dengan sasaran/target lingkaran bertujuan agar atlet dapat mengumpan sesuai sasaran yang ditetapkan dengan tingkat akurasi yang tinggi.

Latihan menggunakan target adalah variasi dalam sebuah latihan seperti yang sudah dilakukan oleh salah satu atlet asal Gorontalo yang juga sebagai atlet sepak takraw Indonesia yang sebagai pengumpan Hasil penelitian Rezki Page | 24
Yusuf Djaina, (2019) terdapat pengaruh Model Latihan Umpan Terhadap Ketepatan Umpan Dalam Permainan Sepak Takraw pada Atlet PPLP Provinsi Gorontalo. Pada penelitian lainya Risky Abdulrahman Pago (2018) yang berjudul Pengaruh Model Latihan umpan jarak bertahap Terhadap Ketepatan umpan Dalam Permainan Sepaktakraw Pada siswa SMP Negeri 1 Telaga. Dengan kesimpulan terdapat Pengaruh Model Latihan umpan jarak bertahap Terhadap Ketepatan umpan Dalam Permainan Sepaktakraw Pada siswa SMP Negeri 1 Telaga..

Dari hasil penelitian diatas dapat disimpulkan bahwa latihan dengan menggunakan ketepatan atau akurasi dapat meningkatkan keterampilan mengumpan, sehingga dapat membantu atlet sepak takraw yang berposisi pengumpan untuk dilatih menggunakan target atau sasaran menggunakan media apapun. Ketepatan dalam mengumpan akan memudahkan seorang smes melaksanakan tugasnya dengan baik semakin tinggi tingkat akurasi pengumpan semakin tinggi pula tingkat ketepatanya, ketepatan adalah persamaan dari kata akurasi istilah akurasi sering digunakan dalam dunia olahraga. Menurut Suharno, (2003) akurasi adalah keterampilan untuk menggerakan suatu objek agar tepat saran, sehingga tujuannya tercapai dengan baik. Akurasi dalam mengumpan sangat dibutuhkan supaya terhindar dari blok lawan menurut Palmizal, (2011) akurasi adalah untuk mengarahkan objek dengan tujuan diinginkan dibutuhkan akurasi yang merupakan kemampuan gerak yang tepat. Ditambahkan oleh Sukadiyanto, (2005) Kemampuan akurasi ke arah sasaran dipengaruhi oleh koordinasi gerak mata dan koordinasi merupakan hasil perpaduan kinerja dari kualitas otot, tulang dan persendian dalam menghasilkan satu 17 gerakan yang efektif dan efisien.

Puslatcab adalah singkatan dari pusat latihan cabang olahraga diamana cabang olahraga sepak takraw masuk dalam program PUSLATCAB 2020 oleh KONI Kota Surabaya, ISSN 2620-6668 (cetak) 
cabang olahraga sepak takraw satu di antara cabang olahraga permainan yang selalu masuk dalam program tersebut setiap tahunya. Setiap tahun jumlah atlet bisa nambah dan juga bisa turun tergantung pada kebutuhan angaran yang ada di DISPORA maupun di KONI Kota Surabaya.

Suksesnya seorang melakukan smesh tergantung pada umpan yang di berikan oleh seorang feeder (penguman) point / angka yang didapat akan lebih mudah jika seorang pengumpan melaksanakan tugasnya dengan baik. Kondisi sangat ini atlet puslatcab sebagian besar baik itu seorang feeder maupun tekong sering melakukan kesalahan dalam mengumpan baik itu bolanya lewat kepada lawan ataupun tingkat akurasinya rendah itu bisa dilihat dalam statistic dala satu permainan jika mengumpan 15 kali salah mengumpan sebanyak 7 -10 kali itu artinya tingkat kesalahan mengumpan sangat tinggi sehingga lawan mudah menyerang dan mendapatkan angka sementara metode latihan biasanya menggunakan metode drill. Kali ini peneliti yang juga sebagai pelatih sepak takraw akan mencoba menggunakan target lingkaran dalam upaya meningkatkan kemampuan akurasi umpan seorang. Permainan target dapat digunakan untuk membantu atlet berlatih konsentrasi, dan ketepatan target sehingga atlet dapat terlatih untuk melakukan umpan kearah sasaran secara tepat. Permainan target juga merupakan permainan yang menyenangkan sehingga atlet tidak akan jenuh untuk mengikuti treatment untuk mengatasi kesulitan melakukan umpan tepat sasaran. Berdasarkan apa yang telah peneliti paparkan di atas, maka peneliti bermaksud menguji cobakan penelitian target untuk mengatasi kelemahan mengumpan ke arah target untuk meningkatkan akurasi mengumpan.

\section{METODE PENELITIAN}

Penelitian ini termasuk penelitian eksperimen. Sugiyono, (2015) menyatakan bahwa penelitian eksperimen merupakan penelitian untuk mencari pengaruh perlakuan tertentu terhadap kondisi yang terkendali. Pada penelitian ini, pengaruh yang dilihat adalah pengaruh permainan target terhadap kemampuan mengumpan. Salah satu tugas penting dalam penelitian adalah menetapkan ada tidaknya hubungan sebab akibat antara fenomena-fenomena dan menarik hukum-hukum tentang hubungan sebab akibat itu. Penelitian eksperimen adalah suatu penelitian yang selalu dilakukan dengan maksud untuk melihat akibat dari suatu perlakuan yang telah diberikan dalam waktu tertentu (Arikunto, 2010:9). Penelitian eksperimen ini menggunakan desain "Pre-test dan Post-test".

Rumus:

$$
0_{1} \rightarrow \times \rightarrow 0_{2}
$$

Keterangan:

$0_{1}=$ Nilai pretest (Sebelum Perlakuan)

$x=$ Treatment (Perlakuan)

$0_{2}=$ Nilai Postest ( Setelah Perlakuan)

Populasi menurut Sugiyono, (2015:117) Populasi adalah "generalisasi yang terdiri atas objek/subjek yang mempunyai kualitas dan karakteristik tertentu yang ditetapkan oleh peneliti untuk dipelajari dan kemudian ditarik kesimpulannya". Populasi dalam penelitian ini adalah PUSLABCAB Sepak takraw Surabaya.

Sampel menurut Sugiyono, (2015: 118) "sebagian yang diambil dari populasi disebut sampel". Sampel penelitian adalah "suatu objek yang akan menjadi bahan penelitian". Adapun untuk menentukan besarnya sampel yang akan diteliti, peneliti menggunakan teknik sampling kuota yang dimana untuk menentukan jumlah sampel berdasarkan jumlah kuota yang diinginkan sesuai kriteria tertentu (Sugiyono, 2015:124). Maka peneliti akan mengambil sampel sebanyak 20 atlet dengan kriteria yang pernah mengikuti kompetisi antar sekolah pada atlet yang mengikuti program PUSLABCAB. Penenlitan ini dilakukan Pada bulan januari minggu ke 2 
(dua) hingga februari minggu 2 (dua) 2019 di SMKN 1 Surabaya tempat kegiatan.

Instrumen penelitian ini mempunyai tingkat validitas dan reliabilitas, instrumen yang valid berarti dapat digunakan untuk mengukur apa yang seharusnya diukur, dan reliabel berarti bila digunakan beberapa kali akan tetap mengasilkan data yang sama. Menurut Sugiyono, (2015:148) instrument penelitian adalah "suatu alat yang digunakan mengukur fenomena alam maupun sosial yang diamati. Instrumen dalam penelitian ini menggunakan tes keterampilan mengumpan dalam permainan sepak takraw seperti pada gambar berikut:

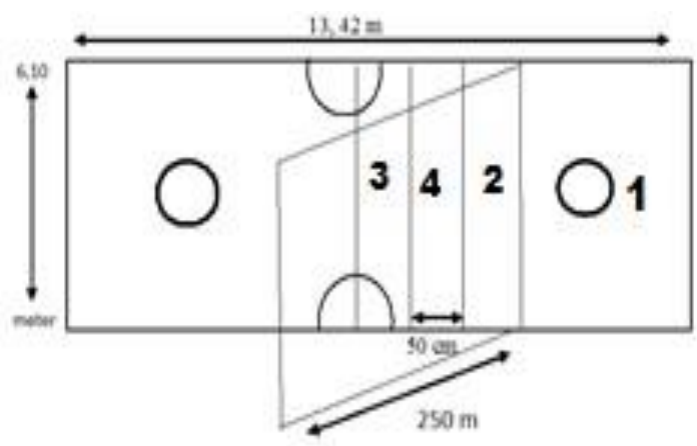

Gambar 1. Tes Keterampilan Mengumpan

Berikut adalah nilai rujukan hasil tes keterampilan sepak takraw utuk teknik mengumpan:

Tabel 1 Norma Tes Mengumpan

\begin{tabular}{lll}
\hline No & Norma & Hasil \\
\hline 1 & Baik Sekali & $>34$ \\
\hline 2 & Baik & $33-34$ \\
\hline 3 & Sedang & $30-32$ \\
\hline 4 & Kurang & $27-29$ \\
\hline 5 & Kurang Sekali & $<27$ \\
\hline
\end{tabular}

\section{HASIL}

Penelitian dilakukan selama 1,5 bulan di Bompa (Yuni Satria Sumana, 2015:75) mengatakan bahwa "for an athlete to perform adequately, at least 8-12 training lessons per micro-cycle is necessary", maka penelitian dilaksanakan selama 12 kali pertemuan yaitu pada hari Senin, Rabu, Jumat, dan Sabtu. Berdasarkan data hasil penelitian, sebagian besar atlet mengalami peningkatan dalam tes ketepatan mengumpan. Hal ini dapat dilihat bahwa sebagian besar atlet memiliki skor selisih yang besar. Skor selisih tersebut diperoleh dengan mengurangkan skor post-test dengan skor pre-test. Dari 20 anak, hanya tiga anak yang tidak mengalami peningkatan ketepatan mengumpan setelah melakukan 6 kali treatement selama 12 kali pertemuan.

Berikut ini merupakan tabel deskripsi hasil tes akurasi mengumpan seperti diskrisi penghitungan statistic.

Tabel 2. Deskripsi Data

\begin{tabular}{clllll}
\hline \multicolumn{5}{c}{ Descriptive Statistics } \\
\hline & N & Min & Max & Mean & Std. Dev \\
\hline Pre Test & 20 & 20.00 & 160.00 & 90.5000 & 43.10025 \\
\hline Post Test & 20 & 60.00 & 180.00 & 137.000 & 27.54900 \\
\hline $\begin{array}{c}\text { Valid N } \\
\text { (listwise) }\end{array}$ & 20 & & & & \\
\hline
\end{tabular}

Dari hasil data di atas terdapat rata-rata pre-test 90.5000 sedangkan pos test 137.0000 setelah di berikan perlakuan .

Tabel 3. Uji Normalitas

\begin{tabular}{lllllll}
\hline \multicolumn{7}{c}{ Tests of Normality } \\
\hline & Statistic & Df & Sig. & Statistic & Df & Sig \\
\hline $\begin{array}{l}\text { Pre } \\
\text { Test }\end{array}$ & .125 & 20 & .200 & .954 & 20 & .426 \\
\hline $\begin{array}{l}\text { Post } \\
\text { Test }\end{array}$ & .181 & 20 & .083 & .913 & 20 & .073 \\
\hline
\end{tabular}

Berdasarkan data pada tabel di atas, maka dapat disimpulkan bahwa hasil uji normalitas pada data penelitian diperoleh nilai signifikan semua lebih besar dari $p$-value 0.05 yang di baca adalah sig, maka data berdisitribusi normal pre test maupun pos test.

Tabel 4. Uji Homogenitas

\begin{tabular}{lllll}
\hline \multicolumn{5}{l}{ Test of Homogeneity of Variances } \\
\hline & $\begin{array}{l}\text { Levene } \\
\text { Statistic }\end{array}$ & $\mathrm{df} 1$ & $\mathrm{df} 2$ & Sig. \\
\hline Pre Test & .889 & 1 & 18 & .358 \\
\hline Post Test & .505 & 1 & 18 & .486 \\
\hline
\end{tabular}

Berdasarkan data pada tabel di atas, maka dapat disimpulkan bahwa hasil uji homogenitas diperoleh nilai signifikan semua lebih besar dari $p$-value 0.05 , maka data berdisitribusi homoogen. 
Hal ini menunjukan syarat untuk uji t bisa di lanjutkan.

Tabel 5. Uji T Paired Sample Test

\begin{tabular}{|c|c|c|c|c|c|c|c|c|c|}
\hline & \multicolumn{9}{|c|}{ Paired Samples Test } \\
\hline & \multicolumn{6}{|c|}{ Paired Differences } & \multirow[b]{2}{*}{$\mathrm{T}$} & \multirow{2}{*}{$\begin{array}{l}d \\
f\end{array}$} & \multirow{2}{*}{$\begin{array}{l}\text { Sig. } \\
\text { (2tai } \\
\text { led) }\end{array}$} \\
\hline & & $\begin{array}{l}\text { Mea } \\
n\end{array}$ & $\begin{array}{l}\text { Std. } \\
\text { Dev }\end{array}$ & $\begin{array}{l}\text { Std. } \\
\text { Error }\end{array}$ & $\begin{array}{r}95 \\
\text { Confi } \\
\text { e Int } € \\
\text { of } t \\
\text { Differ }\end{array}$ & $\begin{array}{l}\text { enc } \\
\text { val } \\
\text { e } \\
\text { nce }\end{array}$ & & & \\
\hline$P$ & Pre_te & - & 46.4 & 10.3 & 27.7 & - & 1 & & \\
\hline ai & st ${ }^{-}$ & 46.5 & 8429 & 9420 & 4468 & 4. & 9 & & \\
\hline$r$ & Post_t & 0000 & & & & 7 & & & \\
\hline 1 & est ${ }^{-}$ & & & & & 4 & & & \\
\hline
\end{tabular}

Berdasarkan dari tabel di atas, menunjukkan bahwa data dari kelompok eksrperimen pre-test dan post-test terdapat ada perbedaan atau ada pengaruh, antara data masing-masing variabel.

\section{PEMBAHASAN}

Permainan target merupakan model latihan yang menarik untuk anak-anak anak remaja. Hal ini terbukti dari hasil statistic deskritif yang mana 20 anak dapat mengumpan ke sasaran dengan lebih baik, dibandingkan dengan hasil pre tes. Hal ini dapat terjadi karena emosi atlet yang masih belum stabil pada masa remaja terjadi peningkatan kepekaan emosi. Menurut pendapat Hadisasmita \& Syarifuddin, (1996) Latihan yang dilakukan dengan biasanya banyak menuntut waktu, pikiran, dan tenaga. Karena itu perludilakukan usahan-usaha untuk mencegah timbulnya kebosanan berlatih, misalnya denga cara merencanakan dan menyelenggarakan variasi-variasi dalam latihan. Sedangkan menurut Djoko Pekik Irianto, (2018) untuk menghindari kebosanan, pelatih harus mampu menciptakan bertbagai variasi latihan baik metode maupun bentuk latihan dengan tidak mengabaikan sasaran yang telah ditetapkan dan perencanaan latihan. Seperti gambar dibawah ini:.

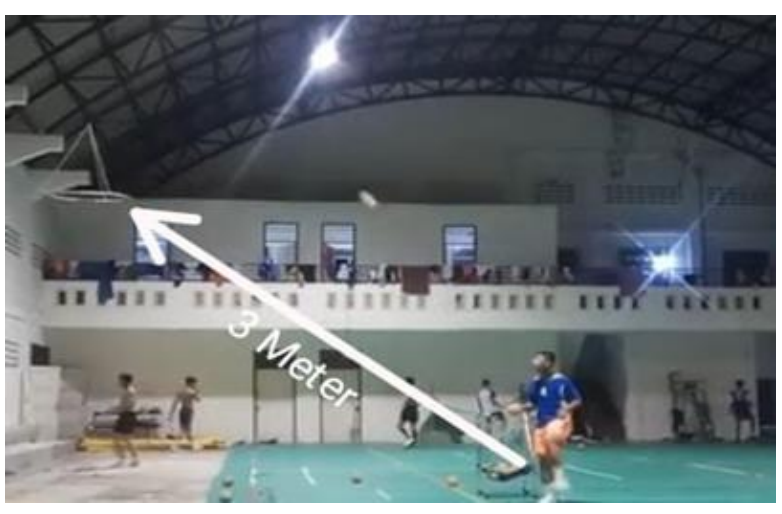

Gambar 2. Variasi latihan akurasi

Hasil uji hipotesis menunjukkan ada pengaruh positif dan signifikan permainan target terhadap kemampuan mengumpan dalam permainan sepak takraw pada atlet Puslatcab Koni Kota Surabaya. Hasil penelitian ini memiliki pengaruh yang sangat signifikan. Hasil penelitian Rezki Yusuf Djaina, (2019) terdapat pengaruh Model Latihan Umpan Terhadap Ketepatan Umpan Dalam Permainan Sepak Takraw pada Atlet PPLP Provinsi Gorontalo.

Rita Eka Izzaty, (2008) menyatakan bahwa emosi yang tinggi pada remaja disebabkan karena remaja mendapatkan tekanan sosial dan menghadapi kondisi baru. Secara biologis, remaja juga mengalami perkembangan. Santrock, (2003) menyatakan bahwa proses perkembangan biologis merupakan perubahan-perubahan dalam hal fisik individu. Proses ini meliputi gen yang diwariskan oleh orang tua, perkembangan otak, pertambahan berat badan, keterampilan motorik serta perubahan hormonal. Kadar hormon yang dimiliki seseorang berpengaruh terhadap emosinya. Variasi latihan dapat membantu atlet dan pelatih dalam melawan kejenuhan dalam latihan, latihan yang panjang seperti TC (Training Camp) memerlukan banyak variasi latihan, dalam variasi latihan juga membantu mengurangi kejenuhan yang berdampak pada terjadinya cedera dalam proses latihan. Pelatih harus banyak menggunakan metode dalam melatih salah satunya untuk menambah gairah atlet dalam berlatih latihan akurasi menggukan target dalam latihan mengumpan salah satu metode 
variasi latihan untk mencari solusi dalam peningkatan keterampilan mengumpan, atlet biasanya mudah tertantang menggunakan media atau alat latihan baru untuk membuktikan mkemampuannya. Latihan target dalam permainan sepak takraw sudah ada dalam nomor pertandingan sepak takraw hoope dengan bergantinya tahun nomor tersebut sudah tidak dipertandingkan lagi. Dalam artikel beberapa dicabang olahraga lain latihan menggunakan target dapat meningkatkan akurasi menendang, melempar dll..

Faktor - faktor yang mempengaruhi mengumpan pada tiga atlet yang mengalami penurunan dalam melakukan mengumpan dalam post - test setelah melakukan pre - test, yaitu kekuatan otot kaki yang tidak seimbang atau tidak kuat saat perkenaan kaki pada bola, sikap badan saat melakukan mengumpan tidak sesuai dengan teknik dasar pada umumnya namun posisi kaki terlalu tinggi ketika mengangkat sehingga bola dapat melambung tinggi keatasnya jauh dari sasaran, konsentrasi pada atlet kurang sehingga dapat munculnya emosi yang tinggi pada siswa yang mengakibatkan terjadinya dalam mengumpan tidak tepat sasaran, dan perkenaan kaki pada bola tidak tepat dalam mengumpan secara tepat sasaran.

\section{SIMPULAN DAN REKOMENDASI}

Simpulan penelitian ini sebagian besar atlet mengalami peningkatan dalam tes akurasi mengumpan, latihan menggunakan target baik digunakan dalam usaha meningkatkan akurasi mengumpan dalam permainan sepak takraw latihan menggukanakan target tidak harus digunakan pada posisi feeder atau pengumpan saja bisa dilakukan kepada tekong maupun smeser Latihan yang baik dan benar selalu mengedepankan prinsip - prinsip latihan metode latihan baiknya selalu berubah - ubah dengan tidak meninggalkan norma - norma latihan untuk menjaga suasana latihan dan tujuan latihan. Suasana latihan yang baik akan berpengaruh terhadap performa latihan, variasi latihan latihan wajib digunakan untuk menghilangkan kejenuhan dalam proses latihan jangka panjang.

\section{UCAPAN TERIMAKASIH}

Penulis mengucapkan puji syukur kedada allah SWT dan banyak terimakasih kepada pengurus PSTI Kota Surabaya, teman - teman pelatih PUSLATCAB dan atlet PUSLATCAB sepak takraw Surabaya yang sudah membantu mensukseskan kegiatan penelitian ini. Tidak lupa juga kami ucapkan terimaksih kepada lembaga tercinta Unipa Surabaya dan Prodi Penjas yang sudah mensuport penelitian ini.

\section{REFERENSI}

Aziz Abdul Hakim, Sudarsono, dan Bulqini Arif. 2007. SepakTakraw. Surabaya: Unesa University Press.

Bompa, T.O., \& Half, G. (2009). Periodezation Theory and Methodology of Training, 5thedition. lowa: Kendall/Hunt.

Finanlampir. Albertus. (2020). Ilmu Kepelatihan Olahraga. Surabaya: Jakad Publishing Media.

Hadisasmita, Yusuf dan Syarifudin, Aip. 1996. Ilmu Kepelatihan Dasar. Departemen Pendidikan dan Kebudayaan Direktorat Jendral Pendidikan Tinggi Proyek Pendidikan Tinggi Tenaga Akademik, Jakarta.

Hanafi. Moh, Aziz Abdul Hakim, dan Arif Bulqini. 2016. Buku Ajar Sepak Takraw. Adi Buana university Press.

Hanafi. M, Rangga. B. P, Margisal. U.T. 2019. Metodologi Kepelatihan Olahraga. Surabaya: Jakad Publishing.

Hanif, Achmad Sofyan. 2015. Kepelatihan Dasar Sepak Takraw. Rajawali Pers: Jakarta.

Hanif, Achmad Sofyan. 2015. Sepak Takraw untuk Pelajar. Rajawali Pers: Jakarta.

Izzaty, Rita Eka, dkk. 2008. Perkembangan Peserta Didik. Yogyakarta: UNY Press.

Pekik Djoko Irianto. (2018). Dasar - Dasar Latihan Olahraga untuk Menjadi Atlet Juara. Bantul: Pohon Cahaya. 
Rahman Rizki Pago. (2018). Pengaruh Model Latihan umpan jarak bertahap Terhadap Ketepatan umpan Dalam Permainan Sepaktakraw Pada siswa SMP Negeri 1 Telaga. Skripsi: niversitas Negeri Gorontalo.

Sugiyono, 2015. Metode Penelitian Pendidikan. Alfabeta : Bandung.

Santrock, J.W. (2012). Life-Span Development. (Terjemah:Benedictine Widyasinta). Jakarta: Penerbit Erlangga.Sarlito Wirawan Sarwono. (2006). Psikologi Remaja. Jakarta: PT Rajagrafindo.

Yusuf R, I. D. (2019). Pengaruh Model Latihan Umpan Terhadap Ketepatan Umpan Dalam Permainan Sepak Takraw pada Atlet PPLP Provinsi Gorontalo. Skripsi Universitas Negeri Gorontalo.

Yuni Satria Sumana. (2015). Pengaruh Latihan Permainan Target Terhadap Peningkatan Ketepatan Tendangan Shooting Menggunakan Punggung Kaki Siswa Peserta Ekstrakurikuler Futsal Di SMP 2 Jetis Bantul. Diunduhdari:http://eprints.uny.ac.id/24850, pada hari Jumat, tanggal 25 Maret 2016.Pukul 13.15 WIB. 